\title{
Implications of the $\mathrm{O}+\mathrm{OH}$ reaction in hydroxyl nightglow modeling
}

\author{
P. J. S. B. Caridade ${ }^{1}$, J.-Z. J. Horta ${ }^{1,2}$, and A. J. C. Varandas ${ }^{1}$ \\ ${ }^{1}$ Departamento de Química, Universidade de Coimbra, 3004-535 Coimbra, Portugal \\ ${ }^{2}$ Universidad Camilo Cienfuegos, Matanzas, Cuba
}

Correspondence to: A. J. C. Varandas (varandas@qtvs1.qui.uc.pt)

Received: 1 February 2012 - Published in Atmos. Chem. Phys. Discuss.: 1 March 2012

Revised: 29 November 2012 - Accepted: 10 December 2012 - Published: 2 January 2013

\begin{abstract}
The hydroxyl nightglow has been examined anew using calculated rate constants for the key reactive and inelastic $\mathrm{O}+\mathrm{OH}\left(v^{\prime}\right)$ quenching processes. These constants have been obtained from quasiclassical trajectories run on the adiabatic ab initio-based double many-body expansionIV potential energy surface for the ground state of the hydroperoxil radical. Significant differences in the vertical profiles of vibrationally excited hydroxyl radicals are obtained relative to the ones predicted by Adler-Golden (1997) when employing an $\mathrm{O}+\mathrm{OH}\left(v^{\prime}\right)$ effective rate constant chosen to be twice the experimental value for quenching of $\mathrm{OH}\left(v^{\prime}=1\right)$. At an altitude of $90 \mathrm{~km}$, such deviations range from $\sim 80 \%$ for $v^{\prime}=1$ to only a few percent for $v^{\prime}=9$. Other mechanisms reported in the literature have also been utilized, in particular those that loosely yield lower and upper limits in the results, namely sudden-death and collisional cascade. Finally, the validity of the steady-state hypothesis is analysed through comparison with results obtained via numerical integration of the master equations.
\end{abstract}

\section{Introduction}

Well known mysteries in the terrestrial atmosphere (Crutzen, 1997), many still unsolved, have stimulated the study of reactions and chemical cycles (Slanger et al., 1988; Toumi et al., 1996; Varandas, 2002, 2005b) in the middle atmosphere (stratosphere and mesosphere). One important contribution arises from the non-local thermodynamic equilibrium or non-LTE hypothesis (also referred to in previous work by local thermodynamic disequilibrium, Varandas, 2003) for the molecular internal degrees of freedom (López-Puertas and Taylor, 2001). The concept of non-LTE was introduced in the context of stellar atmospheres by Milne (1930), while Spitzer
Jr. (1949) first pointed out the possibility that, at the low pressures found in the Earth's upper atmosphere, the radiative field could perturb the state of LTE. The first application of a non-LTE formulation in the terrestrial atmosphere was by Curtis and Goody (1956) in their study of the $\mathrm{CO}_{2} 15 \mu \mathrm{m}$ cooling rate in the mesosphere.

Due to the low pressures and temperatures at high atmospheric altitudes, the lifetimes of the vibrational excitation of molecules may be substantial, i.e., emission often happens prior to collisional de-excitation. When non-LTE conditions hold, the chemistry changes dramatically due to the differences in the internal energy content of the species involved: endothermic reactions become exothermic with rate constants substantially larger, at times orders of magnitude larger (Silveira et al., 2004; Varandas, 2005b). Although several studies have been devoted to the role of vibrationally excited species in reactions, particularly for the $\mathrm{HO}_{\mathrm{x}} \mathrm{cy}-$ cle, atmospheric chemistry models of the middle-upper atmosphere neglect non-LTE (see, e.g., von Clarmann et al., 2010 and references therein). Indeed, it has become a standard procedure to consider non-LTE radiative processes associated with vibrational and rotational excitation in radiative transfer modeling and remote sensing data analysis whenever appropriate (e.g., Funke et al., 2001a,b; Kaufmann et al., 2003; Yankovsky and Manuilova, 2006), but consideration of these effects in chemistry modelling has been neglected (von Clarmann et al., 2010). One of the reasons for this, as has been pointed out (McDade et al., 1987; Adler-Golden, 1997), is the lack of accurate state-to-state deactivation and state-specific rate constants for key reactions involved in the atmospheric cycles. Another is the absence of accurate vertical profiles for the various different vibrationally excited species. 
An important instance of excited molecules and non-LTE in the atmosphere is the cooling of excited hydroxyl radicals through radiative vibrational-rotational transitions within the ${ }^{2} \Pi$ electronic state. This intense emission dominates the nightglow visible spectrum and was first reported by Meinel (1950), thereafter becoming known as Meinel bands. Although more than 60 years have elapsed, a full understanding of the hydroxyl nightglow has not been achieved.

It is common wisdom that the production of vibrationally excited hydroxyl radical is the outcome of the Bates and Nicolet (1950) mechanism

$\mathrm{H}+\mathrm{O}_{3} \rightarrow \mathrm{OH}(v)+\mathrm{O}_{2}$

The nascent $\mathrm{OH}$ is produced mostly in high vibrational states (Charters et al., 1971; Murphy, 1971; Ohoyama et al., 1985), $v=7,8$, peaking at 9 . The mechanism leading to the population of lower states, which are responsible for the intense Meinel bands emission, is still a subject of controversy (McDade et al., 1987). The lower vibrational states can be produced through radiative emission

$\mathrm{OH}\left(v^{\prime}\right) \rightarrow \mathrm{OH}\left(v^{\prime \prime}\right)+h v$

and/or by collisional deactivation

$\mathrm{OH}\left(v^{\prime}\right)+Q \rightarrow \mathrm{OH}\left(v^{\prime \prime}\right)+Q$

where $Q$ is the quencher. McDade and Llewellyn (1987) suggested two limiting cases for the relaxation of the hydroxyl radical via Reaction (R3). The first model, denoted by "sudden-death", assumes that no relaxation process contributes to the population of lower states, i.e. a chemical quenching process. The second, "collisional cascade", assumes that the lower states are obtained via one-quantum vibrational transitions. Using these two limiting cases, several groups (McDade and Llewellyn, 1988; Melo et al., 1997) obtained effective reaction and vibrational relaxation rate constants by analysing the brightness of the 8-3 Meinel band. The analysis of McDade and Llewellyn (1987), based on ground-based observations, led to a reasonable description of the altitude-integrated $\mathrm{OH}$ vibrational distribution, which may not necessarily be consistent with altitude profiles of the individual levels (McDade et al., 1987).

Rationalization of the nightglow spectrum depends strongly on the kinetics data and vertical profiles of $\mathrm{OH}(v)$, and is highly relevant for atmospheric remote sensing (Pickett and Peterson, 1996). Major difficulties arise from the inaccuracies in the absolute Einstein coefficients for the hydroxyl spontaneous emission and the use of different vibrational and reaction rate constants. For example, early work (Finlayson-Pitts and Kleindienst, 1981; Greenblatt and Wiesenfeld, 1982) suggested that many of the vibrational deactivation rate coefficients used at that time might be in error and the conclusions regarding the Meinel bands could be incorrect (McDade, 1991).

One of the references used for atmospheric modelling is the work by Adler-Golden (1997), hereinafter abbreviated as
AG. Using experimental observations, AG proposed a set of state-to-state vibrational relaxation rate constants and Einstein coefficients that are consistent with the laboratory measurements and atmospheric observations. Although reproducing the rocket observations of the nightglow (McDade et al., 1987), a limitation of the Adler-Golden (1997) work is associated with the $\mathrm{O}+\mathrm{OH}(v)$ reaction. Since the relaxation rate constant for $v>1$ was unknown, a vibrationally independent effective quenching was fixed at twice the value of the experimental total removal rate (Spencer and Glass, 1977). Such a value seems to be corroborated (Pickett et al., 2006) by upper atmospheric measurements, although it has also been questioned (von Clarmann et al., 2010) since its use results in predictions of a smaller population of hydroxyl radicals than observed. Quoting the authors (von Clarmann et al., 2010), "it may provide an upper limit for the reaction". Indeed, the topic has long been a matter of uncertainty. Persisting doubts have most recently been expressed by Xu et al. (2012) as "The question of whether the reaction with or quenching by atomic oxygen depends on the $\mathrm{OH}$ vibrational level could not be resolved; assumptions of vibrational level dependence and independence both gave good fits to the observed emissions." This follows previous argumentation (Smith et al., 2010) where the question of the vibrational dependence of the rate of removal of $\mathrm{OH}(v)$ by atomic oxygen was raised in association with the development of the SABER (Sounding of the Atmosphere using Broad-band Emission Radiometry) data analysis algorithms. The authors utilized a value of $5 \times 10^{-11} \mathrm{~cm}^{3} \mathrm{~s}^{-1}$ for the rection with $\mathrm{OH}(v=9)$ and $\mathrm{OH}(v=8)$, which is about twice the reaction rate of the ground state of $\mathrm{OH}$ with atomic oxygen at mesospheric temperatures and essentially coincidental with the calculated value (Varandas, 2004a) for $\mathrm{OH}(v=9)$. Moreover, it has been noted (Mlynczak, 2008) that using the rate constant of $\sim 3 \times 10^{-10} \mathrm{~cm}^{3} \mathrm{~s}^{-1}$, reported (Copeland et al., 2006) from laboratory measurements but still about half of the most recently proposed value (Kalogerakis et al., 2011), would give unphysically large values of atomic oxygen concentration, energy deposition, and heating rates.

To assess the role of the $\mathrm{O}+\mathrm{OH}(v)$ reaction in $\mathrm{OH}$ nightglow modelling, accurate and reliable state-to-state vibrational relaxation and state-specific $\mathrm{O}_{2}$ formation rate constants are required. Using quasi-classical trajectories, a detailed dynamical study under non-LTE conditions has been reported by Varandas (2004a, 2007). This work will be revisited and implications of the $\mathrm{O}+\mathrm{OH}(v)$ reaction in atmospheric modelling analyzed. For this, the reported (Varandas, 2004a, 2007) state-specific rate constant for the $\mathrm{O}_{2}$ formation will be employed. Using the results obtained from the batches of trajectories that were previously run (Varandas, 2004a, 2007), state-to-state vibrational relaxation rate constants for the $\mathrm{O}+\mathrm{OH}(v)$ reaction were extracted for temperatures ranging from 110 to $300 \mathrm{~K}$, and will be presented in Sect. 2. Analysis of the vibrationally excited hydroxyl radical vertical profiles is carried out using the 
steady-state hypothesis for the kinetics mechanism and reported in Sect. 3. To assess the validity of the steady-state condition, the numerical integration of the differential equations has also been performed. In Sect. 4, the major results are stated and discussed.

\section{The $\mathrm{O}+\mathrm{OH}(v)$ reaction}

The $\mathrm{O}+\mathrm{OH}$ reaction has been widely studied experimentally as it is of key importance in many interdisciplinary areas (Miller et al., 1990; Smith et al., 2004; Varandas, 2007; Smith et al., 2010; Kalogerakis et al., 2011). Despite the relevance of this reaction, most theoretical studies have focused on the reactive component by assuming a Boltzmann distribution for the internal degrees of freedom. However, a detailed study using a non-equilibrium distribution has also been performed (Varandas, 2004a, 2007) for both the reaction

$\mathrm{O}+\mathrm{OH}\left(v^{\prime}\right) \rightarrow \mathrm{O}_{2}+\mathrm{H}$

and vibrational quenching

$\mathrm{O}+\mathrm{OH}\left(v^{\prime}\right) \rightarrow \mathrm{O}+\mathrm{OH}\left(v^{\prime \prime}\right)$

by using quasiclassical trajectory (QCT) methods (Hase et al., 1996) at temperatures between 110 and $450 \mathrm{~K}$. The details of these vibrational state-specific calculations which are re-analyzed in this paper can be found in Varandas (2004a). Thus, we only highlight the relevant aspects concerning the present work.

The calculations employed the QCT method and the popular double many-body potential energy surface (Pastrana et al., 1990) (DMBE IV) for $\mathrm{HO}_{2}\left({ }^{2} A^{\prime \prime}\right)$. The DMBE IV form is an ab initio based potential function that has been extensively employed in studies of the $\mathrm{O}+\mathrm{OH}$ reaction and its reverse, using both quantum (Lin et al., 2006) and classical (Varandas, 2005b) methods. Indeed, special care has been taken to achieve a realistic description of the atomdiatom long-range forces, through the inclusion of dispersion and electrostatic energy components. Although new surfaces have been reported (Xie et al., 2007) from high-level ab initio methods, they may not describe long-range forces adequately since they are based on interpolation schemes and rely on the accuracy of the raw data. In fact, despite having been published in 1990, DMBE IV remains amongst the reference potential energy surfaces (PESs) in the literature (Lin et al., 2006) for $\mathrm{HO}_{2}\left({ }^{2} A^{\prime \prime}\right)$.

The QCT calculations reported elsewhere (Varandas, 2004a) use for each temperature a steady-state distribution that mimics the vibrational states of $\mathrm{OH}$ in the upper atmosphere (Varandas, 2003), while effective nascent rotational micro-populations (personal communication by P. C. Cosby in Varandas, 2004a; see also Cosby and Slanger, 2007) have been utilized for the six OH Meinel bands (4-0, 5-1, 6-1, 7-2, 8-3, 9-4). Two methods (I and II) have been described by Varandas (2004a) and differ in the way the maximum impact parameter is treated. Method I, uses a impact parameter which is fixed at the same value for all initial vibrational states, while in method II is vibrationally state-specific. In the analysis which follows we have employed the results of method I since they cover a wider temperature range, and provide results which are statistically the same as method II. The final vibrational state analysis of $\mathrm{OH}$ and $\mathrm{O}_{2}$ has been carried out semi-classically (Hase et al., 1996). To check for variations in the rate constant due to statistical errors reported in the original work (Varandas, 2004a), additional trajectories have been integrated but the resulting numerical values remain within the significant figures of the originally reported rate constants.

The rate constant for vibrational quenching is calculated using the expression

$k_{(\mathrm{R} 5)}^{v^{\prime} \rightarrow v^{\prime \prime}}=g_{\mathrm{e}}(T)\left(\frac{8 k_{\mathrm{B}} T}{\pi \mu}\right)^{1 / 2} \pi b_{\max }^{2} N^{v^{\prime} \rightarrow v^{\prime \prime}} / N^{v^{\prime}}$

where $k_{\mathrm{B}}$ is the Boltzmann constant, $\mu$ the reduced mass of the reactants, $b_{\max }$ the maximum impact parameter, $N^{v^{\prime} \rightarrow v^{\prime \prime}}$ the number of trajectories in a total of $N^{v^{\prime}}$, and $g_{\mathrm{e}}(T)=2\{[5+3 \exp (-228 / T)+\exp (-326 / T)][2+$ $2 \exp (-205 / T)]\}^{-1}$ the electronic degeneracy factor which takes into account the fine structure of $\mathrm{O}\left({ }^{3} \mathrm{P}\right)$ and $\mathrm{OH}\left({ }^{2} \Pi\right)$. A similar expression can be derived for the reactive part, Reaction (R4), by substituting $N^{v^{\prime} \rightarrow v^{\prime \prime}} / N^{v^{\prime}}$ with the reactive probability. Table 1 gathers the state-to-state vibrationalrelaxation and state-specific rate constants for $\mathrm{H}+\mathrm{O}_{2}$ formation. Although the error bars of up to $5 \%$ or so in some of the cross sections cannot warrant the reported number of decimal places for some of the tabulated rate constants, a fixed format has been adopted for convenience in all cases. Note that both the inelastic

$\mathrm{O}_{a}+\mathrm{O}_{b} \mathrm{H}\left(v^{\prime}\right) \rightarrow \mathrm{O}_{a}+\mathrm{O}_{b} \mathrm{H}\left(v^{\prime \prime}\right)$

and atom-exchange reactive channels

$\mathrm{O}_{a}+\mathrm{O}_{b} \mathrm{H}\left(v^{\prime}\right) \rightarrow \mathrm{O}_{b}+\mathrm{O}_{a} \mathrm{H}\left(v^{\prime \prime}\right)$

count as vibrational relaxation processes when $v^{\prime} \neq v^{\prime \prime}$. For comparison, total removal rate constants reported in Varandas (2004a, 2007) are also shown in Table 1.

A well known problem in QCT is that the method cannot account for quantum mechanical effects. For example, since we are dealing with a light atom, tunnelling can be an important issue. However, the calculated rate constants are generally in good agreement with the best reported data, and is even valid for systems as light as $\mathrm{H}+\mathrm{H}_{2}$ (Zhao et al., 1990). Another issue that cannot be overlooked in QCT methods is the problem of zero-point energy leakage (ZPE) (see Varandas, 2007 for earlier work on this topic). Due to the high exoergicity, ZPE leakage should be negligible for Reactions (R4) and (R5). 
Table 1. State-to-state, state-to-all, and state-specific rate constants (multiplied by $10^{12}$ ) for the $\mathrm{O}+\mathrm{OH}(v)$ reaction.

\begin{tabular}{|c|c|c|c|c|c|c|c|c|c|c|c|c|}
\hline \multirow[b]{2}{*}{$v^{\prime}$} & \multicolumn{10}{|c|}{$k_{(\mathrm{R} 5)}^{v^{\prime} \rightarrow v^{\prime \prime}} / \mathrm{cm}^{3} \mathrm{~s}^{-1}$} & \multirow[t]{2}{*}{$k_{(\mathrm{R} 4)}^{v^{\prime}} / \mathrm{cm}^{3} \mathrm{~s}^{-1}$} & \multirow[t]{2}{*}{$\eta_{v}(T)$} \\
\hline & $v^{\prime \prime}=0$ & 1 & 2 & 3 & 4 & 5 & 6 & 7 & 8 & all & & \\
\hline \multicolumn{13}{|c|}{$T=110 \mathrm{~K}$} \\
\hline 1 & 35.5 & & & & & & & & & 35.5 & 41.1 & 1.16 \\
\hline 2 & 14.9 & 15.5 & & & & & & & & 30.4 & 40.4 & 1.33 \\
\hline 3 & 14.5 & 10.1 & 10.1 & & & & & & & 34.7 & 40.4 & 1.16 \\
\hline 4 & 7.2 & 12.5 & 8.4 & 9.1 & & & & & & 37.2 & 45.6 & 1.23 \\
\hline 5 & 7.4 & 6.2 & 7.8 & 5.8 & 6.2 & & & & & 33.4 & 41.5 & 1.24 \\
\hline 6 & 6.3 & 6.3 & 8.1 & 10.3 & 3.6 & 5.4 & & & & 29.7 & 39.8 & 1.34 \\
\hline 7 & 3.5 & 4.7 & 4.2 & 6.4 & 5.5 & 3.1 & 4.7 & & & 32.1 & 51.9 & 1.62 \\
\hline 8 & 3.2 & 2.3 & 2.7 & 3.0 & 1.6 & 3.9 & 4.1 & 5.4 & & 26.2 & 54.5 & 2.08 \\
\hline 9 & 1.0 & 1.3 & 2.5 & 2.1 & 3.1 & 2.3 & 3.4 & 3.6 & 3.4 & 22.7 & 62.7 & 2.76 \\
\hline \multicolumn{13}{|c|}{$T=160 \mathrm{~K}$} \\
\hline 1 & 28.4 & & & & & & & & & 28.4 & 31.5 & 1.11 \\
\hline 2 & 19.2 & 13.2 & & & & & & & & 32.4 & 30.0 & 0.926 \\
\hline 3 & 13.6 & 9.4 & 6.3 & & & & & & & 29.3 & 37.4 & 1.28 \\
\hline 4 & 9.4 & 8.7 & 6.2 & 5.6 & & & & & & 29.9 & 44.3 & 1.48 \\
\hline 5 & 5.8 & 5.3 & 8.6 & 5.5 & 3.3 & & & & & 28.5 & 37.7 & 1.32 \\
\hline 6 & 5.8 & 5.6 & 4.8 & 4.6 & 3.7 & 4.4 & & & & 28.9 & 40.0 & 1.38 \\
\hline 7 & 3.6 & 3.2 & 5.5 & 3.3 & 4.3 & 2.5 & 5.1 & & & 27.5 & 44.2 & 1.61 \\
\hline 8 & 2.5 & 2.6 & 2.9 & 2.5 & 2.3 & 2.5 & 3.9 & 5.6 & & 24.8 & 48.0 & 1.94 \\
\hline 9 & 1.5 & 1.9 & 1.7 & 3.5 & 2.3 & 2.4 & 3.1 & 2.0 & 4.0 & 22.4 & 54.2 & 2.42 \\
\hline \multicolumn{13}{|c|}{$T=210 \mathrm{~K}$} \\
\hline 1 & 20.2 & & & & & & & & & 20.2 & 34.2 & 1.69 \\
\hline 2 & 12.0 & 13.3 & & & & & & & & 25.3 & 31.9 & 1.26 \\
\hline 3 & 10.2 & 7.3 & 11.3 & & & & & & & 28.8 & 30.5 & 1.06 \\
\hline 4 & 9.8 & 7.9 & 7.1 & 5.5 & & & & & & 30.3 & 36.8 & 1.21 \\
\hline 5 & 2.1 & 5.3 & 8.4 & 4.9 & 4.3 & & & & & 25.0 & 32.2 & 1.29 \\
\hline 6 & 2.6 & 4.9 & 5.7 & 3.9 & 4.5 & 2.6 & & & & 24.2 & 39.3 & 1.62 \\
\hline 7 & 3.2 & 3.2 & 2.9 & 4.1 & 4.2 & 3.2 & 3.9 & & & 24.7 & 38.7 & 1.57 \\
\hline 8 & 4.1 & 2.9 & 2.1 & 1.9 & 2.1 & 2.7 & 2.9 & 2.7 & & 21.4 & 45.2 & 2.11 \\
\hline 9 & 1.8 & 1.8 & 1.4 & 2.2 & 2.1 & 1.3 & 1.9 & 2.3 & 2.6 & 17.4 & 50.7 & 2.91 \\
\hline \multicolumn{13}{|c|}{$T=255 \mathrm{~K}$} \\
\hline 1 & 21.0 & & & & & & & & & 21.0 & 24.8 & 1.18 \\
\hline 2 & 12.4 & 11.4 & & & & & & & & 23.8 & 27.3 & 1.15 \\
\hline 3 & 8.5 & 10.5 & 7.4 & & & & & & & 26.4 & 32.7 & 1.24 \\
\hline 4 & 7.5 & 7.0 & 6.7 & 5.8 & & & & & & 27.0 & 32.2 & 1.19 \\
\hline 5 & 5.7 & 5.4 & 6.3 & 5.8 & 4.7 & & & & & 27.9 & 32.1 & 1.15 \\
\hline 6 & 4.6 & 4.0 & 4.4 & 5.4 & 3.5 & 4.2 & & & & 26.1 & 33.1 & 1.27 \\
\hline 7 & 3.6 & 3.4 & 3.0 & 3.7 & 3.2 & 3.2 & 4.1 & & & 24.2 & 37.2 & 1.54 \\
\hline 8 & 2.4 & 2.3 & 2.4 & 2.2 & 2.2 & 2.6 & 2.9 & 3.9 & & 20.9 & 42.8 & 2.05 \\
\hline 9 & 1.5 & 1.3 & 1.5 & 1.8 & 1.9 & 1.8 & 2.2 & 2.4 & 3.1 & 17.5 & 45.4 & 2.59 \\
\hline \multicolumn{13}{|c|}{$T=300 \mathrm{~K}$} \\
\hline 1 & 19.2 & & & & & & & & & 19.2 & 21.1 & 1.10 \\
\hline 2 & 14.2 & 10.5 & & & & & & & & 23.8 & 23.9 & 1.00 \\
\hline 3 & 9.4 & 9.6 & 8.1 & & & & & & & 25.8 & 28.4 & 1.10 \\
\hline 4 & 6.4 & 7.8 & 6.9 & 4.8 & & & & & & 25.4 & 28.8 & 1.13 \\
\hline 5 & 6.3 & 4.7 & 6.0 & 3.8 & 3.8 & & & & & 24.6 & 31.7 & 1.29 \\
\hline 6 & 4.6 & 4.4 & 5.0 & 4.7 & 4.1 & 4.5 & & & & 27.4 & 29.7 & 1.09 \\
\hline 7 & 3.4 & 3.1 & 3.6 & 3.3 & 3.5 & 3.1 & 4.0 & & & 25.2 & 34.9 & 1.38 \\
\hline 8 & 2.4 & 2.3 & 2.4 & 2.4 & 2.1 & 2.7 & 3.0 & 4.2 & & 22.3 & 39.3 & 1.76 \\
\hline 9 & 1.2 & 1.3 & 2.1 & 1.8 & 2.0 & 1.7 & 1.8 & 2.1 & 3.3 & 18.2 & 43.4 & 2.38 \\
\hline
\end{tabular}




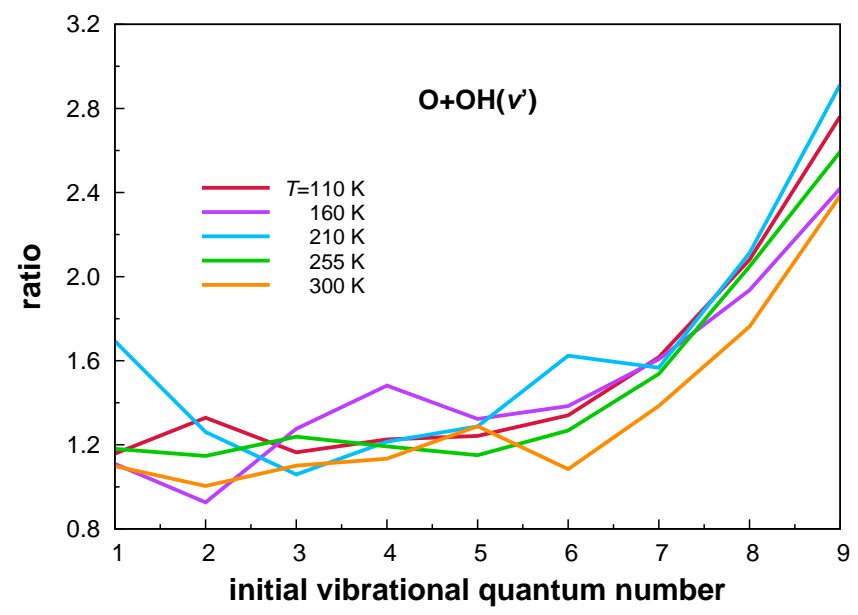

Fig. 1. Ratios between reactive and total vibrational relaxation as a function of the initial vibrational state of the hydroxyl molecule and temperature.

A salient feature of the data reported in Table 1 is the importance of multi-quanta transitions for the vibrational relaxation over the whole range of temperatures. In particular, for high vibrational quantum numbers the rate constant is, within the statistical error, almost constant irrespectively of the vibrational state. For low vibrational quantum states, $v^{\prime}=1$ for example, the tendency is for the rate to diminish with temperature. For a better comparison between the two competing processes, Fig. 1 shows the branching ratios $\eta_{v^{\prime}}(T)=k_{(\mathrm{R} 4)}^{v^{\prime}}(T) / k_{(\mathrm{R} 5)}^{v^{\prime}}$ all $(T)$. It can be seen that they display a roughly $T$-independent pattern, with $\eta_{v^{\prime}}$ increasing sharply with the initial quantum number for $v^{\prime} \geq 6$. In all cases, the dominant contribution for large $v^{\prime}$ is the reactive contribution. This can be understood from the role played by the highly stretched $\mathrm{OH}$ molecule, which favours bondbreaking. Moreover, the large reactive rate constant at low temperatures can be understood from the prevailing longrange forces as described by capture-type models (Clary and Werner, 1984; Varandas, 1987). One then expects the rate constant to decrease with temperature. Also relevant is the enhancement of the rate constant for $\mathrm{H}+\mathrm{O}_{2}$ formation with increasing $v^{\prime}$.

Khachatrian and Dagdigian (2005) reported a total removal rate constant for $\mathrm{OH}(v=1)$ at room-temperature of $3.9 \pm 0.6 \times 10^{-11} \mathrm{~cm}^{3} \mathrm{~s}^{-1}$. The recommended values of International Union of Pure and Applied Chemistry (IUPAC) (Atkinson et al., 2004) and National Aeronautics and Space Administration (NASA) (Sander et al., 2011) are $3.5 \pm 0.1$ and $3.3 \pm 0.7 \times 10^{-11} \mathrm{~cm}^{3} \mathrm{~s}^{-1}$, respectively. The rate constant for $\mathrm{OH}(v=0)$ is $\sim 2.7 \times 10^{-11} \mathrm{~cm}^{3} \mathrm{~s}^{-1}$ (Varandas, 2004a). In turn, the QCT result (Varandas, 2004a) with $\mathrm{OH}(v=1)$ for $T=255 \mathrm{~K}[300 \mathrm{~K}]$ is $(4.6 \pm 0.2) \times$ $10^{-11} \mathrm{~cm}^{3} \mathrm{~s}^{-1}\left[(4.0 \pm 0.3) \times 10^{-11} \mathrm{~cm}^{3} \mathrm{~s}^{-1}\right]$, in very good agreement with the experimental and recommended values. The value utilized by Adler-Golden (1997) originates from the experimental work of Spencer and Glass (1977). However, because the relaxation rate constant for $v>1$ was unknown, AG adopted a vibrationally independent effective quenching equal to twice the value of the experimental total removal rate, namely $20 \times 10^{-11} \mathrm{~cm}^{3} \mathrm{~s}^{-1}$. Clearly, his value overestimates by far both the experimental/recommended and the theoretical data from the present work. Marshall et al. (2002) studied the relaxation of $\mathrm{OH}\left(v^{\prime}\right)$ by laser-induced fluorescence, having reported a preliminary value of $k=4.6 \times$ $10^{-11} \mathrm{~cm}^{3} \mathrm{~s}^{-1}$ for $v^{\prime}=2$ at room-temperature. The QCT result is $k(T=255 \mathrm{~K})=(5.1 \pm 0.1) \times 10^{-11} \mathrm{~cm}^{3} \mathrm{~s}^{-1}$ (Varandas, 2004a) and $(4.8 \pm 0.1) \times 10^{-11} \mathrm{~cm}^{3} \mathrm{~s}^{-1}$ for $T=300 \mathrm{~K}$, again in good agreement with experiment.

As noted in the Introduction, Kalogerakis et al. (2011) have recently reported collisional removal rate constants of $\mathrm{OH}(v=9)$ by several quenchers using laser fluorescence spectroscopy to measure the steady-state population. The predicted value of the $\mathrm{O}+\mathrm{OH}(v=9)$ vibrational relaxation rate constant was $4 \pm 1 \times 10^{-10} \mathrm{~cm}^{3} \mathrm{~s}^{-1}$, thus nearly 7 times larger than the one here utilized. Although a reason for the smaller theoretical value may be ascribed to unknown subtleties of the $\mathrm{HO}_{2}$ PES or even nonadiabatic effects that could not have been taken into account, there are issues that obscure any definite conclusion at present. In particular, as noted above, the use of very large rate constants have been found to yield unrealistic values of $[\mathrm{H}],[\mathrm{O}]$ and mesospheric chemical heating rate (Mlynczak, 2008). Although Kalogerakis et al. (2011) expressed the belief that the tendency for smaller rate constant values is due to the uncertainty of some parameters used in the kinetic models, and that the SABER data will yield more accurate results when using high rate constant values, such a result has not been observed in the work of Xu et al. (2012) who reported "a value of $6.465 \pm 0.785 \times 10^{-11} \mathrm{~cm}^{3} \mathrm{~s}^{-1}$,, only about $20 \%$ larger than the calculated value for $\mathrm{OH}(v=9)$.

\section{Kinetics mechanism and input data}

For altitudes between 80 and $100 \mathrm{~km}$, it is commonly accepted that vibrationally excited $\mathrm{OH}$ radicals are produced essentially via the Bates and Nicolet (1950) mechanism:

$\mathrm{H}+\mathrm{O}_{3} \rightarrow \mathrm{OH}\left(v^{\prime}\right)+\mathrm{O}_{2}$

with the product $\mathrm{OH}$ showing an inverted vibrational distribution that peaks at $v^{\prime}=9$. In turn, the standard ozone source is the fast three-body recombination process

$\mathrm{O}+\mathrm{O}_{2}+M \rightarrow \mathrm{O}_{3}+M$

where $M=\mathrm{N}_{2}, \mathrm{O}_{2}$, and $\mathrm{O}$, are all in the ground electronic state. While the rate of $\mathrm{OH}\left(v^{\prime}\right)$ formation can be equated to the one of ozone formation, Reaction (R9), the most 
important depletion processes of $\mathrm{OH}\left(v^{\prime}\right)$ are

$$
\begin{aligned}
\mathrm{OH}\left(v^{\prime}\right)+\mathrm{O}_{2} & \rightarrow \mathrm{OH}\left(v^{\prime \prime}\right)+\mathrm{O}_{2} \\
\mathrm{OH}\left(v^{\prime}\right)+\mathrm{N}_{2} & \rightarrow \mathrm{OH}\left(v^{\prime \prime}\right)+\mathrm{N}_{2} \\
\mathrm{OH}\left(v^{\prime}\right)+\mathrm{O} & \rightarrow \mathrm{OH}\left(v^{\prime \prime}\right)+\mathrm{O} \\
\mathrm{OH}\left(v^{\prime}\right)+\mathrm{O} & \rightarrow \mathrm{O}_{2}+\mathrm{H} \\
\mathrm{OH}\left(v^{\prime}\right) & \rightarrow \mathrm{OH}\left(v^{\prime \prime}\right)+h v
\end{aligned}
$$

The mechanism defined by Reactions (R8) to (R14) can be generalized to account for other sources and sinks of $\mathrm{O}_{3}$ and $\mathrm{OH}(v)$. For example, although it has been noted (AdlerGolden, 1997) that the reaction $\mathrm{O}+\mathrm{HO}_{2}$ could be a potential candidate, previous work (Kaye, 1988) has shown that it is unlikely to play a crucial role in studies of the high atmosphere. Although this assumption is possibly valid for $\mathrm{HO}_{2}$ in the ground vibrational state as the dynamics only yields $\mathrm{OH}\left(v^{\prime} \leq 6\right)$, the argument no longer holds if nonLTE is considered, since up to $\mathrm{OH}(v=15)$ products can then be formed (Silveira et al., 2004; Varandas, 2005b). In addition, the reaction of $\mathrm{OH}+\mathrm{O}_{3}$ has been shown to yield $\mathrm{HO}_{2}$ vibrationally excited above the classical asymptote for dissociation, and thus can be another potential source of $\mathrm{OH}\left(v^{\prime}\right)$ (Varandas and Zhang, 2001; Zhang and Varandas, 2001). Furthermore, from the so-called $\mathrm{HO}_{y+3}$ mechanisms (Varandas, 2002) (where $y=0,1,2$ labels the number of $\mathrm{O}$ atoms in the hydrogen-oxygen species (Varandas, 2003), where $y=0$ for $\mathrm{HO}_{3}$ ), one may have to pay attention to the reaction $\mathrm{OH}\left(v^{\prime}\right)+\mathrm{O}_{2}\left(v^{\prime \prime}\right)$ as a potential sink of vibrationally excited $\mathrm{OH}$. For the sake of discussion and comparison width AG's work, these extra complications will not be considered further in this paper.

From Reactions (R8) to (R9) and using the steady-state assumption for $\mathrm{O}_{3}$, one gets:

$k_{(\mathrm{R} 8)}[\mathrm{H}]\left[\mathrm{O}_{3}\right]=\sum_{M} k_{(\mathrm{R} 9)}^{M}[\mathrm{O}]\left[\mathrm{O}_{2}\right][M]$

while for $\left[\mathrm{OH}\left(v^{\prime}\right)\right]$ the result is:

$$
\begin{aligned}
& {\left[\mathrm{OH}\left(v^{\prime}\right)\right]=\left\{\omega_{\mathrm{OH}\left(v^{\prime}\right)} \sum_{M} k_{(\mathrm{R} 9)}^{M}[\mathrm{O}]\left[\mathrm{O}_{2}\right][M]\right.} \\
& +k_{(\mathrm{R} 11)}^{v^{\prime}+1 \leq 9 \rightarrow v^{\prime}}\left[\mathrm{N}_{2}\right]\left[\mathrm{OH}\left(v^{\prime}+1 \leq 9\right)\right] \\
& \left.+\sum_{v^{*}=v^{\prime}+1}^{9}\left[k_{(\mathrm{R} 10)}^{v^{*} \rightarrow v^{\prime}}\left[\mathrm{O}_{2}\right]+k_{(\mathrm{R} 12)}^{v^{*} \rightarrow v^{\prime}}[\mathrm{O}]+A_{v^{\prime} \leftarrow v^{*}}\right]\left[\mathrm{OH}\left(v^{*}\right)\right]\right\} \\
& \quad\left\{k_{(\mathrm{R} 11)}^{v^{\prime} \rightarrow v^{\prime}-1}\left[\mathrm{~N}_{2}\right]+k_{(\mathrm{R} 13)}[\mathrm{O}]\right. \\
& \left.+\sum_{v^{*}=0}^{v^{\prime}-1}\left[k_{(\mathrm{R} 10)}^{v^{\prime} \rightarrow v^{*}}\left[\mathrm{O}_{2}\right]+k_{(\mathrm{R} 12)}^{v^{\prime} \rightarrow v^{*}}[\mathrm{O}]+A_{v^{\prime} \leftarrow v^{*}}\right]\right\}^{-1}
\end{aligned}
$$

where $A_{v^{\prime} \leftarrow v^{\prime \prime}}$ are the Einstein coefficients for spontaneous emission of Reaction (R14), and $\omega_{\mathrm{OH}\left(v^{\prime}\right)}$ the nascent distribution of $\mathrm{OH}\left(v^{\prime}\right)$ states. The summations over $M$ cover $\mathrm{N}_{2}, \mathrm{O}_{2}$ and $\mathrm{O}$. The vertical profiles can be evaluated recursively starting from $v^{\prime}=9$, where the terms in the numerator of the right hand side of Eq. (3) serve as sources of
$\mathrm{OH}\left(v^{\prime}\right)$ (including cascade) while the ones in the denominator refer to depletion. Thus, the contributions that originate from relaxation of higher $v^{\prime}$ states have been considered as a source of $\mathrm{OH}\left(v^{\prime} \leq 8\right)$ but any excitation from lower $v^{\prime}$ states is neglected. This is justifiable since these state-tostate vibrational-excitation rate constants are expected to be very small at the temperatures of interest (Varandas, 2004a) and to the best of our knowledge reliable estimates for these rate constants are lacking. Of course, collisional processes involving vibrationally excited $\mathrm{O}_{2}$ and other species (Caridade et al., 2002; Varandas, 2005b) are not considered in this judgement.

Using the steady-state hypothesis for the same set of reactions, but the AG assumption for Reactions (R12) and (R13) (i.e. cascading via Reaction (R12) is absent), the result is:

$$
\begin{aligned}
{\left[\mathrm{OH}\left(v^{\prime}\right)\right]_{\mathrm{AG}} } & =\left\{\omega_{\mathrm{OH}\left(v^{\prime}\right)} \sum_{M} k_{(\mathrm{R} 9)}^{M}[\mathrm{O}]\left[\mathrm{O}_{2}\right][M]\right. \\
+ & k_{(\mathrm{R} 11)}^{v^{\prime}+1 \leq 9 \rightarrow v^{\prime}}\left[\mathrm{N}_{2}\right]\left[\mathrm{OH}\left(v^{\prime}+1 \leq 9\right)\right] \\
+ & \sum_{v^{*}=v^{\prime}+1}^{9}\left(k_{(\mathrm{R} 10)}^{v^{*} \rightarrow v^{\prime}}\left[\mathrm{O}_{2}\right]+A_{\left.v^{\prime} \leftarrow v^{*}\right)}\left[\mathrm{OH}\left(v^{*}\right)\right]\right\} \\
\times & \left\{k_{(\mathrm{R} 11)}^{v^{\prime} \rightarrow v^{\prime}-1}\left[\mathrm{~N}_{2}\right]+\sum_{v^{*}=0}^{v^{\prime}-1}\left[k_{(\mathrm{R} 10)}^{v^{\prime} \rightarrow v^{*}}\left[\mathrm{O}_{2}\right]\right.\right. \\
+ & \left.\left.k_{(\mathrm{R} 12)+(\mathrm{R} 13)}^{v^{\prime}}[\mathrm{O}]+A_{v^{\prime} \leftarrow v^{*}}\right]\right\}^{-1}
\end{aligned}
$$

with $k_{(R 12)+(R 13)}^{v^{\prime}}=2 \times 10^{-10} \mathrm{~cm}^{-3} \mathrm{~s}^{-1}$ as a $v^{\prime}$-independent effective quenching rate constant.

In turn, the "sudden-death" vertical profiles of McDade and Llewellyn (1987) assume the form

$$
\begin{aligned}
{\left[\mathrm{OH}\left(v^{\prime}\right)\right]_{\mathrm{sd}} } & =\left\{\omega_{\mathrm{OH}\left(v^{\prime}\right)} \sum_{M} k_{(\mathrm{R} 9)}^{M}[\mathrm{O}]\left[\mathrm{O}_{2}\right][M]\right. \\
& \left.+\sum_{v^{*}=v^{\prime}+1}^{9} A_{v^{\prime} \leftarrow v^{*}}\left[\mathrm{OH}\left(v^{*}\right)\right]\right\}\left\{\left(k_{(\mathrm{R} 12)}^{v^{\prime} 0}+k_{(\mathrm{R} 13)}[\mathrm{O}]\right.\right. \\
& \left.+k_{(\mathrm{R} 10)}^{v^{\prime} \rightarrow 0}\left[\mathrm{O}_{2}\right]+\sum_{v^{*}=0}^{v^{\prime}-1} A_{v^{\prime} \leftarrow v^{*}}\right\}^{-1}
\end{aligned}
$$

having the emission process Reaction (R14) as the only source of low $\mathrm{OH}$ vibrational states. In turn, the "collisional cascade" mechanism leads to:

$$
\begin{aligned}
{\left[\mathrm{OH}\left(v^{\prime}\right)\right]_{\mathrm{cc}} } & =\left\{\omega_{\mathrm{OH}\left(v^{\prime}\right)} \sum_{M} k_{(\mathrm{R} 9)}^{M}[\mathrm{O}]\left[\mathrm{O}_{2}\right][M]+\left(k_{(\mathrm{R} 11)}^{v^{\prime}+1 \rightarrow v^{\prime}}\left[\mathrm{N}_{2}\right]\right.\right. \\
& \left.+k_{(\mathrm{R} 10)}^{v^{\prime}+1 \rightarrow v^{\prime}}\left[\mathrm{O}_{2}\right]+k_{(\mathrm{R} 12)}^{v^{\prime}+1 \rightarrow v^{\prime}}[\mathrm{O}]\right)\left[\mathrm{OH}\left(v^{\prime}+1\right)\right] \\
& \left.+\sum_{v^{*}=v^{\prime}+1}^{9} A_{v^{\prime} \leftarrow v^{*}}\left[\mathrm{OH}\left(v^{*}\right)\right]\right\}\left\{k_{(\mathrm{R} 11)}^{v^{\prime} \rightarrow v^{\prime}-1}\left[\mathrm{~N}_{2}\right]\right. \\
& +k_{(\mathrm{R} 13)}[\mathrm{O}]+k_{(\mathrm{R} 10)}^{v^{\prime} \rightarrow v-1}\left[\mathrm{O}_{2}\right]+k_{(\mathrm{R} 12)}^{v^{\prime} \rightarrow v-1}[\mathrm{O}] \\
& \left.+\sum_{v^{*}=0}^{v^{\prime}-1} A_{v^{\prime} \leftarrow v^{*}}\right\}^{-1}
\end{aligned}
$$


In this case, besides the population arising from Reaction (R14), other sources of $\mathrm{OH}\left(v^{\prime}\right)$ are the one-quantum relaxation Reactions (R10), (R11) and (R12). Note that in the original formulation of McDade and Llewellyn (1987) the quenching by $\mathrm{N}_{2}$ was not considered explicitly. It should be pointed that $\mathrm{AG}$ used the assumption above on the rate of the $\mathrm{O}+\mathrm{OH}(v)$ reaction to extract the degree of multiquantum relaxation for the main oxygen molecule collider via comparison with available experimental data. For consistency, we should therefore re-evaluate the $\mathrm{OH}(v)+\mathrm{O}_{2}$ data using our own set of $\mathrm{O}+\mathrm{OH}(v)$ rate constants, as pointed out by an anonymous Referee to whom we wish to thank. Clearly, this task lies out of the scope of the present work. The assumption is therefore made that the values extracted by AG for the other reactions are still realistic. Whether this is truly the case remains to be seen either empirically by redoing AG's work or through the use of accurate experimental/theoretical stateto-state results, which to our knowledge are unavailable.

The temperature and concentration profiles employed in our calculations have been taken from the US Naval Research Laboratory Mass Spectrometer and Incoherent Scatter Radar 2000 (NRLMSISE 2000) which gathers revised $\mathrm{O}_{2}$ and $\mathrm{O}$ densities in the lower thermosphere (Hedin, 1991; Picone et al., 2002). To compare with experimental measurements we have used the conditions present during the multiple rocket investigation of the nightglow, termed Energy Transfer in the Oxygen Nightglow (ETON), as described in part 5 (McDade et al., 1987) of this series of papers. The parameters considered in the profile database correspond to the conditions during ETON 5, namely: 23 March 1982, $57.36^{\circ} \mathrm{N}, 352.62^{\circ} \mathrm{E}$ and 23:28:23 UTC. The uncertainties in temperature and molecular concentrations are of about $10 \mathrm{~K}$ and $10 \%$, respectively. In turn, the nascent distribution of $\mathrm{OH}\left(v^{\prime}\right)$ states for Reaction (R8) are taken from a renormalization (Adler-Golden, 1997) of the data of Charters et al. (1971); see Fig. 2. Such values have been extrapolated to lower $v^{\prime}$ states using information theory (Steinfeld et al., 1987), and renormalized to the Einstein coefficients of Nelson et al. (1990). Additionally, the three-body recombination rate constants have been taken from Atkinson et al. (2004) which are valid for the temperature range 100$300 \mathrm{~K}$, thus embracing the limits investigated in this work of $169 \mathrm{~K}$ and $206 \mathrm{~K}$ for altitudes between 80 and $100 \mathrm{~km}$, respectively. As for the $\mathrm{OH}\left(v^{\prime}\right)+\mathrm{O}_{2}$ and $\mathrm{OH}\left(v^{\prime}\right)+\mathrm{N}_{2}$ reactions, we have used unaltered the semi-empirical data (AdlerGolden, 1997). Although classical trajectories have been run in our group (Garrido et al., 2002; Caridade et al., 2002) for the $\mathrm{OH}\left(v^{\prime}\right)+\mathrm{O}_{2}\left(v^{\prime \prime}\right)$ reactive and non-reactive processes, no accurate data has yet been reported for the state-to-state vibrational relaxation of $\mathrm{OH}\left(v^{\prime}\right)$ in collisions with $\mathrm{O}_{2}(v=0)$. To account for the influence of variation in temperature on the $\mathrm{O}+\mathrm{OH}\left(v^{\prime}\right)$ rate constants along the vertical profile, a simple interpolation scheme has been utilized.

Key elements for the description of the $\mathrm{OH}$ profiles are the Einstein transition probabilities for radiative transitions.
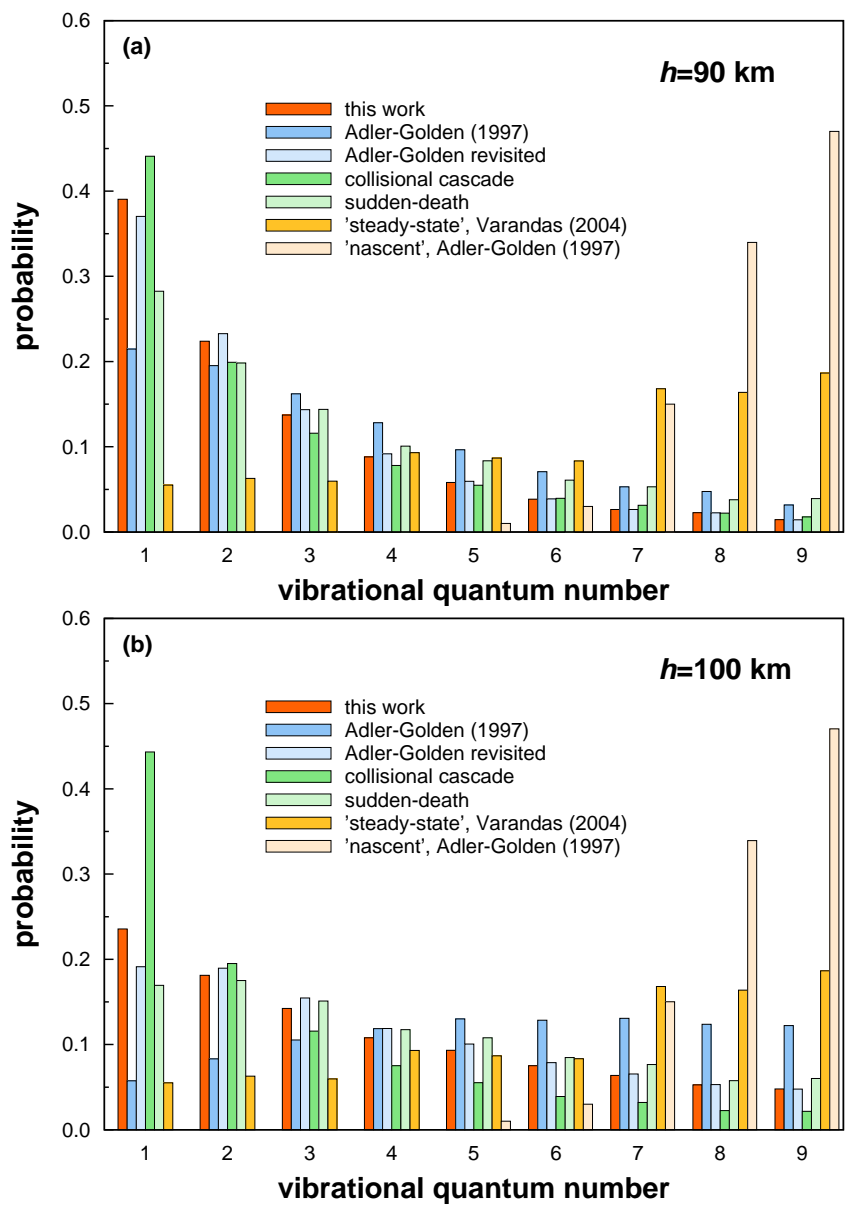

Fig. 2. Vibrational distributions of the hydroxyl radical at (a) $90 \mathrm{~km}$ and (b) $100 \mathrm{~km}$. Also shown for comparison based on the same set of concentrations and rate-constants are: Adler-Golden (1997) results using his estimate for the $\mathrm{O}+\mathrm{OH}(v)$ total rate constant; AdlerGolden scheme revisited using the effective rate constant based on this work; McDade and Llewellyn (1987) "sudden-death" and collisional cascade. Also included is other theoretical data of Varandas (2003) and the "experimental"-renormalized nascent distribution in Reaction (R8) of Charters et al. (1971).

The values most often used in atmospheric modelling are from laboratory measurements of $\Delta v=1$ and $\Delta v=2$ from the work of Nelson et al. (1990). They have been reported (Adler-Golden, 1997) as the most accurate at the time, although for higher overtones the data show strong deviations. Other data sets have been reported in the literature (Turnbull and Lowe, 1989; Langhoff et al., 1986; Murphy, 1971), but all with limitations. Based on the fact that the method used by Turnbull and Lowe (1989) should in principle give accurate results, a correction curve has been reported to scale the rotational average data (Adler-Golden, 1997). Such a correction was based on an inaccurate intensity calibration which leads to a systematic error in function of the band-center frequency. 
Rather than using the above data sets, we have adopted the newly calculated Einstein transition probabilities of van der Loo and Groenenboom $(2007,2008)$ which are based on accurate ab initio data. Using Hund's case (a) (Huber and Herzberg, 1979), each vibrational state wave function $\left|J M_{J}^{2} \Pi_{|\Omega|} p\right\rangle$, is characterized by $J$, the total angular momentum, $M_{J}$, the projection of the vector $\boldsymbol{J}$ on the laboratory-frame z-axis, $|\Omega|=1 / 2,3 / 2$, the total electronic angular momentum projection on the molecular axis and $p= \pm 1$ the spectroscopic parity operator. Since for low rotational states, $\Omega$ is a good quantum number, the wave function is usually labeled by $F_{1}$ when $\Omega=3 / 2$ and $F_{2}$ for $\Omega=1 / 2$. van der Loo and Groenenboom $(2007,2008)$ reported 24660 Einstein coefficients and photoabsorption cross sections for the full set of quantum numbers $\left\{v, J, F_{n}, p\right\}$ for upper and lower states up to $v=10$. The specific rotational band intensities for the $P\left(J^{\prime}\right), Q\left(J^{\prime}\right)$ and $R\left(J^{\prime}\right)$ bands, $J^{\prime \prime}=J^{\prime}+1$, $J^{\prime \prime}=J^{\prime}$, and $J^{\prime \prime}=J^{\prime}-1$, respectively, have been calculated up to $J=121 / 2$. The computed lifetimes reported using such data lie between the best known experimental values, with the error in the calculated frequencies being of $\sim 0.05 \%$.

If we assume a Boltzmann distribution of the rotational states at $T_{\text {rot }}$, the thermally averaged radiative transition probability for the vibrational band $v^{\prime \prime} \leftarrow v^{\prime}$ is defined as (Mies, 1974)

$$
\begin{aligned}
A_{v^{\prime \prime} \leftarrow v^{\prime}}\left(T_{\mathrm{rot}}\right) & =Q_{v^{\prime}}^{-1}\left(T_{\mathrm{rot}}\right) \sum_{J^{\prime}, F_{n}^{\prime}, p^{\prime}, J^{\prime \prime}, F_{n}^{\prime \prime}, p^{\prime \prime}}^{\text {all }}\left(2 J^{\prime}+1\right) \\
& \times A\left(p^{\prime \prime}, F_{n}^{\prime \prime}, J^{\prime \prime}, v^{\prime \prime} \leftarrow p^{\prime \prime}, J^{\prime}, F_{n}^{\prime}, v^{\prime}\right) \\
& \times \exp \left(-E_{v^{\prime} ; J^{\prime}, F_{n}^{\prime}, p^{\prime}} / k_{\mathrm{B}} T_{\mathrm{rot}}\right)
\end{aligned}
$$

with $Q_{v^{\prime}}\left(T_{\text {rot }}\right)$ the electronic-rotational partition function assuming the form:

$$
Q_{v^{\prime}}\left(T_{\mathrm{rot}}\right)=\sum_{J^{\prime}, F_{n}^{\prime}, p^{\prime}}^{\text {all }}\left(2 J^{\prime}+1\right) \exp \left(-E_{v^{\prime} ; J^{\prime}, F_{n}^{\prime}, p^{\prime}} / k_{\mathrm{B}} T_{\mathrm{rot}}\right)
$$

and "all" implying a summation over all available states. Following Wallace (1962), the equivalence of the gas temperature and rotational temperature has been assumed. Although being in general much weaker than the intramultiplets $\left(p^{\prime \prime}=p^{\prime}\right)$ bands, the satellite bands, intermultiplet transitions with $p^{\prime \prime} \neq p^{\prime}$ have also been included.

\section{Implications of the $\mathrm{O}+\mathrm{OH}$ reaction on the $\mathrm{OH}(v)$ profiles}

Using the steady-state hypotheses and the data reported in the previous sections, Fig. 2 shows the distribution of the vibrational excited hydroxyl radical for two altitudes, $h=90$ and $100 \mathrm{~km}$. For $90 \mathrm{~km}$ the vibrational distribution shows an exponential decay with $40 \%$ of the population at the $v=1$ state, a trend which is consistent with all models considered in this work. However, the use of the AG effective rate constant for Reactions (R12) and (R13) predicts a population nearly $50 \%$ less for $v=1$, and becomes the major contributer for vibration levels greater than $v=3$. This clearly shows that the $\mathrm{O}+\mathrm{OH}(v)$ reaction plays an important role for the description of the vibrational-excited hydroxyl radical height-distribution, specially for lower $v$ states. To reinforce such a statement, the AG assumption has also been revisited, hereafter denoted as AGr, using an effective rate constant consistent with the calculations reported in this paper, i.e.

$k_{(\mathrm{R} 12)+(\mathrm{R} 13)}^{v}(T)=k_{(\mathrm{R} 13)}^{v}(T)+k_{(\mathrm{R} 12)}^{v \rightarrow 0}(T)$

The results nearly coincide with those of multi-quantum cascade, since the reactive rate constant Reaction (R13) is dominant (see Fig. 1). Another salient feature is the larger value of the $v=1$ population when considering the collisional-cascade mechanism, which arises from the larger one-quantum rate constants for lower states (see Table 1).

For $100 \mathrm{~km}$ the distribution is somewhat flatter, with the population of lower vibrational states reduced to nearly $25 \%$ for $v=1$. In this case, the AG predictions show an almost negligible population for $v=1$, while for $v=9$ it is almost of the same order of magnitude as the single-collision results. For comparison, the nascent (Ohoyama et al., 1985) and steady-state distributions reported from single collision trajectory dynamics (Varandas, 2003) are also shown in Fig. 2. Although the vibrational distribution reported in this work is far from a thermalized one (supporting in some extent a previous observation, Varandas, 2003), it is significantly different from either of them. The differences with respect to the latter are probably due to the fact that this considered only the $\mathrm{O}+\mathrm{OH}\left(v^{\prime}\right)$ reactions as a source of vibrational deactivation, thus providing a kind of limit to the global kinetics model.

The $\mathrm{OH}\left(v^{\prime}\right)$ vertical profiles for specific vibrational states are shown in Fig. 3 as a function of altitude. The dominant contribution comes from $v=1$ with the maximum value arising at $\sim 87 \mathrm{~km}$, while for other vibrational states, the maximum is shifted upwards. This can be attributed to the increase of the atomic oxygen concentration with height and a decrease of the $\mathrm{O}_{2}$ one, thus reducing the contribution of vibrational relaxation. For a direct comparison with previous results, we have also plotted the total vibrational excited hydroxyl concentration. A fair agreement is observed between the total vertical profile from the current work and the one reported elsewhere (Varandas, 2004b), where stretched oxygen and odd hydrogen species have also been included (Varandas, 2002, 2003, 2004b, 2005a,b) in an attempt to offer clues to help resolve the so-called "ozone deficit problem" and " $\mathrm{HO}_{\mathrm{x}}$ dilemma" in the middle atmosphere under non-LTE.

Figure 4 presents the vertical profiles that result from the various models and rate constants reported in the present 


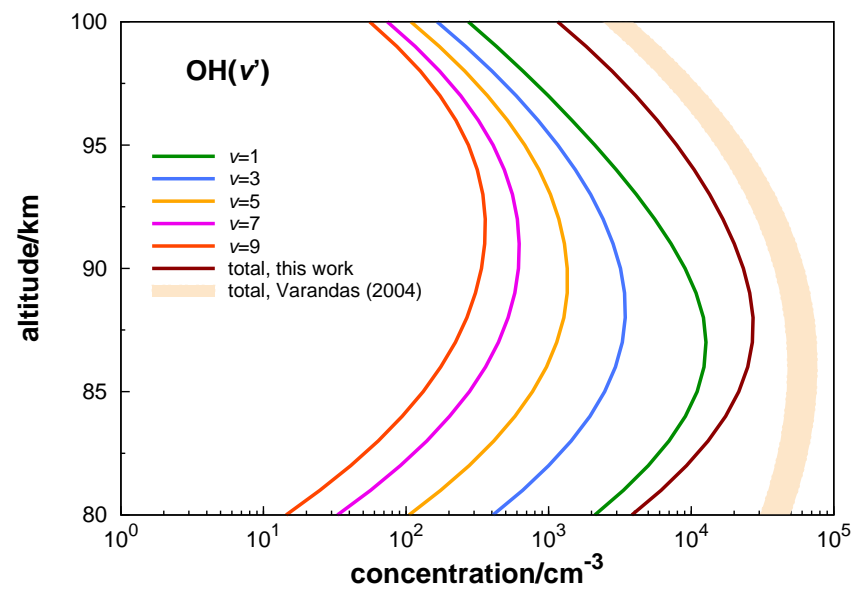

Fig. 3. Vertical profiles of vibrationally excited hydroxyl radical. The shaded area refers to the model reported elsewhere (Varandas, $2004 \mathrm{~b}, 2005 \mathrm{a})$ for the total concentration using satellite data taken in the equatorial region.

work. A comparison of panel (a) with panel (b), clearly indicates the role of the $\mathrm{O}+\mathrm{OH}$ reaction on the vibrational distribution noted above. Above $92 \mathrm{~km}, \mathrm{AG}$ predicts a population inversion, with $v=1$ becoming the less populated state, while AGr shows a similar vibrational distribution as presented in Fig. 3. For the "sudden-death" (sd) and "collisionalcascade" (cc) models, the relative positions of the vertical profiles is ordered according to the vibrational levels of the hydroxyl radical. In the "sd" the vibrationally excited populations are substantially smaller for altitudes higher than $90 \mathrm{~km}$, as a result of the chemical quenching associated with this model. Although not shown (cf. Fig. 3), the behaviour of the total concentration in the "cc" model lies close to the results from a previous model (Varandas, 2002, 2003, 2004b, $2005 a, b)$, suggesting that such data may be viewed as providing an upper limit to the real case. Note, however, that the physical-chemical contents of this model differ somewhat from the ones utilized here since it was based on satellite data in the equatorial region where strong semiannual variations may occur.

For a quantitative analysis, we report in Fig. 5 the relative deviation of the AG (Adler-Golden, 1997) results relative to ours, i.e., $\left\{[\mathrm{OH}(v)]_{\mathrm{AG}}-[\mathrm{OH}(v)]\right\} /[\mathrm{OH}(v)]$. Although the results presented here essentially agree with AG for $v^{\prime}=9$, there are significant deviations for other $v$ values. For high vibrational states and altitudes, the AG results differ by nearly 10 to $20 \%$ for $v=9$ and 7 , respectively, while for low vibrational states the difference reaches nearly $90 \%$ for $v=1$. This is due to the fact that we allow the total $\mathrm{OH}(v)$ to cascade) at each step, including the significant component that is formed during the cascading process. Thus, the AG predictions underestimate our results. However, our predicted total concentrations of $\mathrm{OH}(v)$ show good agreement (within a factor of two or so) with his results. As noted above, a qualitative agreement is also found with the total concentration of
$\mathrm{OH}(v)$ predicted from the Varandas $(2004 \mathrm{~b}, 2005 \mathrm{a})$ non-LTE model.

In summary, significant differences are observed between the $\mathrm{OH}\left(v^{\prime}\right)$ profiles for specific vibrational states determined in this work and the AG results, although the differences are small for the total $\left[\mathrm{OH}\left(v^{\prime}\right)\right]$. Of course, an improved model employing accurate estimates of the rate constants of all the vibrational relaxation and reactive channels involved [in particular those involving collisions of $\mathrm{OH}\left(v^{\prime}\right)$ with $\mathrm{N}_{2}$ and $\mathrm{O}_{2}$ ] will be required to assess which prediction is most realistic. This calls for theoretical and experimental work, as the discrepancies between theory and experiment are particularly large in the vibrational relaxation case (Caridade et al., 2002).

Using the vertical profile for the $v=8$ concentration, the volume emission rate for the 8-3 band has been calculated, and is plotted in Fig. 6. The rotationally averaged Einstein coefficient for the 8-3 transition is obtained from Eq. (7) as a function of altitude via the temperature variation. Also shown in Fig. 6 is the data reported by Adler-Golden (1997) and the data calculated in this work using the AG proposed rate constant, together with visual estimates from the data of ETON 5 (McDade et al., 1987). The maximum value in our analysis occurs at nearly $90 \mathrm{~km}$, similar to the maximum reported in the ETON 5 paper although our results are more intense ( 270 vs. $\sim 150$ photons $\mathrm{cm}^{-3} \mathrm{~s}^{-1}$ ). With increasing altitude all data sets become nearly identical, with our results lying within the experimental error bars.

A critical assumption in this work is the steady-state hypothesis, a condition frequently employed and quite often taken for granted since its proposition in the seminal works of Bodenstein (1913), Chapman and Hunderhill (1913) and Chapman (1930), with Chapmann utilizing it to explain the existence of the ozone layer in the Earth's atmosphere. To check the validity of the steady-state condition in modelling Meinel bands, the set of 9 differential equations corresponding to the vibrationally excited hydroxyl concentrations have been simultaneously solved for all altitudes, taking into account the fast recombination ozone formation Reaction (R9). Several integration methods have been tested, ranging from the simple Euler to the traditional 4th order Runge-Kutta (RK4) and Bulirsch-Stoer approaches. No attempt has been made to use (optimize) a variable step method, or utilize specialized methods for stiff equations. Figure 7 shows the typical varition of vibrationally excited concentrations with time, in this case for $h=100 \mathrm{~km}$ using the RK4 method. Tests using the simpler Euler method result in similar variations. In all cases, the nascent concentrations were taken as the starting point. As expected, the $v=9$ concentration quickly achieves steady-state by balancing its formation with depletion. Since a cascade model is considered, the last concentration achieving a steady-state is the $v=1$ level. Except for $v=9$, all curves pass through a maximum before reaching steady state with the time of the maximum decreasing with increasing $v$. 

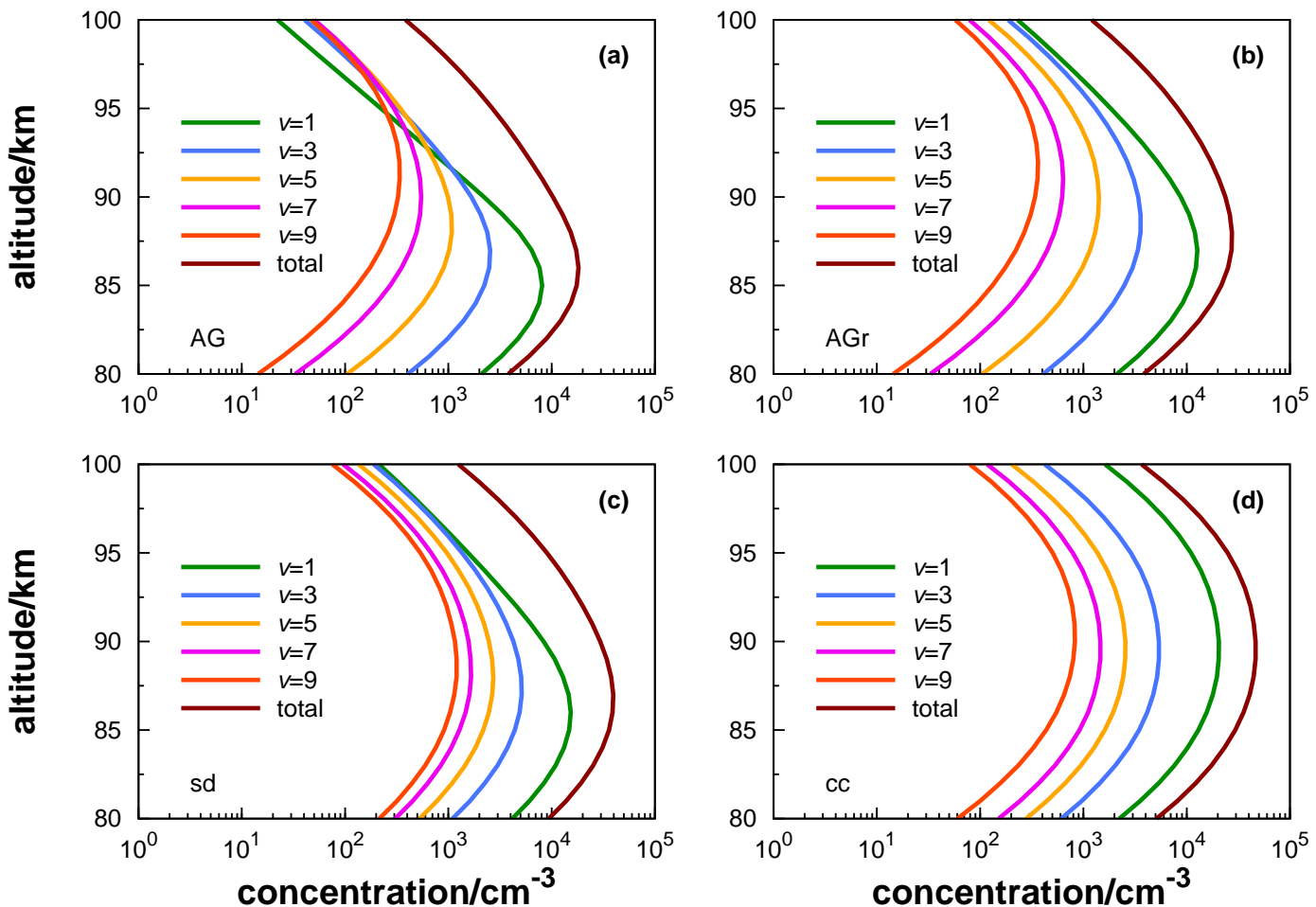

Fig. 4. Vertical profiles of vibrationally excited hydroxyl radical: (a) using the Adler-Golden (1997) O + OH(v) total rate constant; (b) AdlerGolden scheme revisited using the total rate constant from the current work; (c) McDade and Llewellyn (1987) "sudden-death" and (d) collisional cascade mechanisms.

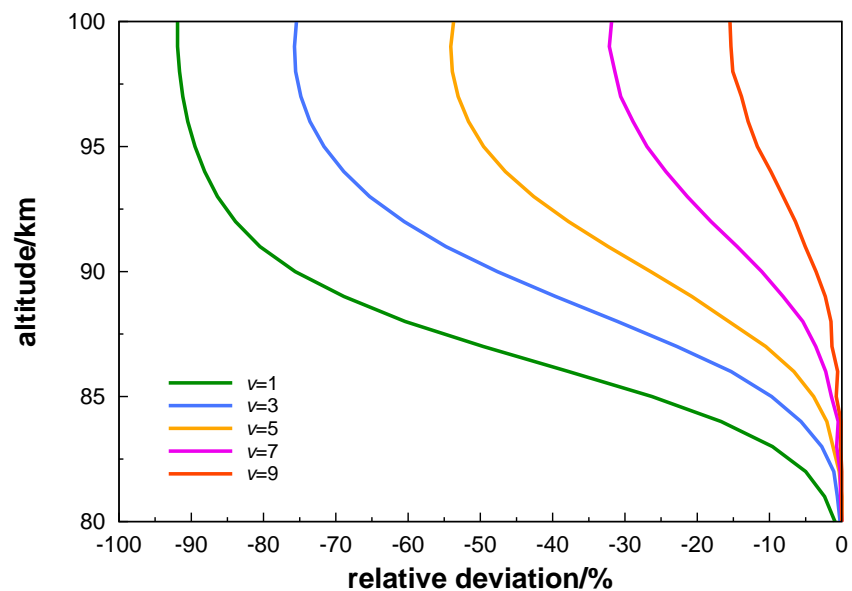

Fig. 5. Vertical profiles of differences between the results obtained with the empirical $\mathrm{O}+\mathrm{OH}\left(v^{\prime}\right)$ rate constant of Adler-Golden (1997) and the ones from the present work based on QCT calculations (Varandas, 2004a).

\section{Conclusions}

Reliable state-to-state vibrational relaxation rate constants for the $\mathrm{O}+\mathrm{OH}\left(v^{\prime}\right)$ reaction have been presented based on earlier theoretical work (Varandas, 2004a, 2007) which employed the quasiclassical trajectory method and the DMBE

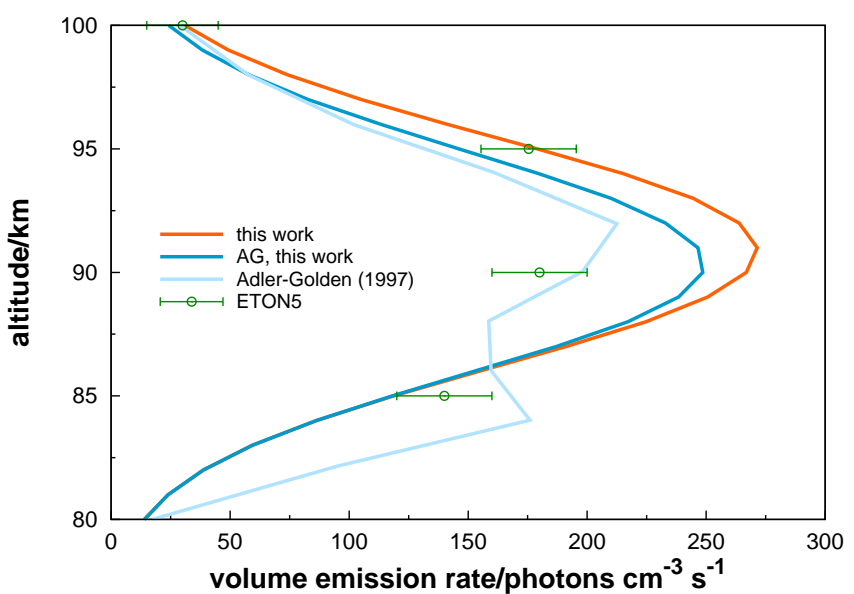

Fig. 6. Vertical profiles of the volume emission rate for the 8-3 band obtained using the empirical $\mathrm{O}+\mathrm{OH}\left(v^{\prime}\right)$ rate constant from AdlerGolden (1997) and those from the present work based on the QCT calculations from Varandas (2004a). Also shown are the originally reported data of Adler-Golden (1997) and the ETON 5 experimental volume emission rate measurements (McDade et al., 1987).

IV ab initio-based potential energy surface. As in previous work, the values reported here show that the reactive part dominates over the whole range of initial vibrational quantum numbers and temperatures. It is predicted that the total 


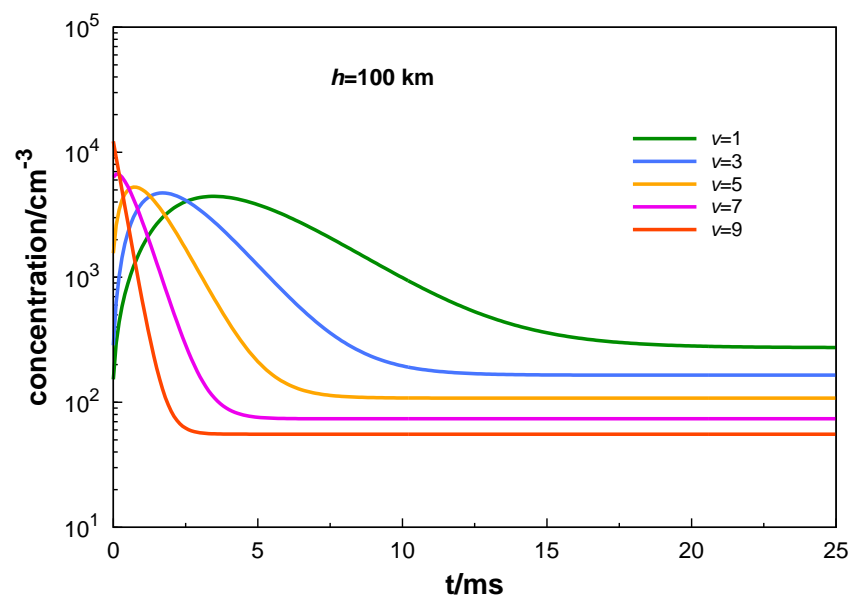

Fig. 7. Variation with time of the concentration of the various $\mathrm{OH}(v)$ species as integrated numerically using the QCT results from Varandas (2004a).

rate constant at room-temperature is significantly smaller than the one used previously for modelling the hydroxyl Meinel bands in the upper stratosphere. Our confidence in the reported results therefore stems from the accuracy of the potential energy surface. This justifies attributing high reliability to the predicted state-to-state and state-specific dynamics and kinetics parameters of the collision processes involving atomic oxygen and hydroxyl radicals in the various vibrational-rotational states.

To assess the role of the $\mathrm{O}+\mathrm{OH}$ reaction in the hydroxyl Meinel bands, the steady-state hypothesis has been utilized, and a comparison with other rate constants and simplified models presented. The more realistic mechanism is possibly the one that describes the lower vibrational states of $\mathrm{OH}$ via the assumption of a collisional cascade process. In this regard, the results from the present work differ significantly from the ones obtained by AG as confirmed by using a realistic value for the effective total $\mathrm{O}+\mathrm{OH}$ quenching rate constant. It is also shown that the results from the limitingcase mechanisms suggested by McDade and Llewellin seem to encompass the total $[\mathrm{OH}(v)]$ obtained from the model of Varandas (2005a,b). As a final remark on the steady-state hypothesis, this work has shown that it offers a reliable working hypothesis for the higher stratosphere and mesosphere at least insofar as the $\mathrm{O}+\mathrm{OH}(v)$ reaction is concerned.

Acknowledgements. J.Z.J.H. thanks III (UC) for financial support, and the UMCC, Cuba, for leave of absence. This work is financed by FEDER through "Programa Operacional Factores de Competitividade - COMPETE" and national funds under the auspices of Fundação para a Ciência e a Tecnologia, Portugal (projects PTDC/QUI-QUI/099744/2008, PTDC/AAC-AMB/099737/2008).

Edited by: W. Ward

\section{References}

Adler-Golden, S.: Kinetic parameters for $\mathrm{OH}$ nightglow modeling consistent with recent laboratory experiments, J. Geophys. Res., 102, 19969-19976, doi:10.1029/97JA01622, 1997.

Atkinson, R., Baulch, D. L., Cox, R. A., Crowley, J. N., Hampson, R. F., Hynes, R. G., Jenkin, M. E., Rossi, M. J., and Troe, J.: Evaluated kinetic and photochemical data for atmospheric chemistry: Volume I - gas phase reactions of $\mathrm{O}_{\mathrm{x}}, \mathrm{HO}_{\mathrm{x}}, \mathrm{NO}_{\mathrm{x}}$ and $\mathrm{SO}_{\mathrm{x}}$ species, Atmos. Chem. Phys., 4, 1461-1738, doi:10.5194/acp-41461-2004, 2004.

Bates, D. R. and Nicolet, M.: The Photochemistry of Atmospheric Water Vapor, J. Geophys. Res., 55, 301-327, doi:10.1029/JZ055i003p00301, 1950.

Bodenstein, M.: Eine Theorie der photochemishen reaktionsgeschwindigkeiten, Z. Physik. Chem., 85, 329-397, 1913.

Caridade, P. J. S. B., Sabin, J., Garrido, J. D., and Varandas, A. J. C.: Dynamics of the $\mathrm{OH}+\mathrm{O}_{2}$ vibrational relaxation process, Phys. Chem. Chem. Phys, 4, 4959-4969, doi:10.1039/b203101a, 2002.

Chapman, D. L. and Hunderhill, L. K.: The interaction of chlorine and hydrogen. The influence of mass, J. Chem. Soc. Trans., 103, 496-508, doi:10.1039/CT9130300496, 1913.

Chapman, S.: A theory of upper-atmospheric ozone, Memoirs Roy. Metereol. Soc., III, 103-125, 1930.

Charters, P. E., Macdonald, R. G., and Polanyi, J. C.: Formation of vibrationally excited $\mathrm{OH}$ by reaction $\mathrm{H}+\mathrm{O}_{3}$, Appl. Opt., 10, 1747-1754, doi:10.1364/AO.10.001747, 1971.

Clary, D. C. and Werner, H. J.: Quantum calculations on the rate constant for the $\mathrm{O}+\mathrm{OH}$ reaction, Chem. Phys. Lett., 112, 346350, doi:10.1016/0009-2614(84)85755-3, 1984.

Copeland, R. A., Smith, A. G., Mlynczak, M. M., and Kalogerakis, K. S.: Deactivation of highly vibrationally excited $\mathrm{OH}$ by $\mathrm{O}$ atoms, Eos Trans AGU, Fall Meet. Suppl., 87, Abstract SA21A0255, 2006.

Cosby, P. C. and Slanger, T. G.: OH spectroscopy and chemistry investigated with astronomical sky spectra, Can. J. Phys., 85, 7799, doi:10.1139/p06-088, 2007.

Crutzen, P.: Mesospheric mysteries, Science, 277, 1951-1952, doi:10.1126/science.277.5334.1951, 1997.

Curtis, A. R. and Goody, R. M.: Thermal variation in the upper atmosphere, Proc. Royal Soc., 193-206, doi:10.1098/rspa.1956.0128, 1956.

Finlayson-Pitts, B. J. and Kleindienst, T. E.: The reaction of hydrogen atoms with ozone as a source of vibrationally excited $\mathrm{OH}\left(X^{2} \Pi_{i}\right)_{v=9}$, J. Chem. Phys., 74, 4533-4543, doi:10.1063/1.441642, 1981.

Funke, B., López-Puertas, M., Stiller, G. P., von Clarmann, T., and Höpfner, M.: A new non-LTE Retrieval Method for Atmospheric Parameters From MIPAS-ENVISAT Emission Spectra, Adv. Space Res., 27, 1099-1104, doi:10.1016/S0273-1177(01)001697, 2001.

Funke, B., Stiller, G. P., von Clarmann, T., Höpfner, M., and LópezPuertas, M.: A New non-LTE Retrieval Method for Atmospheric Parameters from MIPAS-ENVISAT Emission Spectra, in: IRS 2000: Current Problems in Atmospheric Radiation, edited by: Smith, W. L. and Timofeyev, Y. M., 761-764, A. Deepak Publishing, Hampton, Va, USA, 2001.

Garrido, J. D., Caridade, P. J. S. B., and Varandas, A. J. C.: Dynamics study of the $\mathrm{OH}+\mathrm{O}_{2}$ branching atmospheric reaction. 4. Influence of vibrational relaxation in collisions involving 
highly excited species, J. Phys. Chem. A, 106, 5314-5322, doi:10.1021/jp0203245, 2002.

Greenblatt, G. D. and Wiesenfeld, J. R.: Time-resolved emmision studies of vibrationally excited hydroxyl radicals: $\mathrm{OH}\left(X^{2} \Pi, v=9\right)$, J. Geophys. Res., 87, 1145-1152, doi:10.1029/JC087iC13p11145, 1982.

Hase, W. L., Duchovic, R. J., Hu, X., Komornicki, A., Lim, K. F., Lu, D., Peslherbe, G. H., Swamy, K. N., Linde, S. R. V., Varandas, A. J. C., Wang, H., and Wolf, R. J.: VENUS96: A General Chemical Dynamics Computer Program, QCPE Bull., 16, p. 43, 1996.

Hedin, A. E.: Extension of the MSIS thermophere model into the middle and lower thermophere, J. Geophys. Res., 96, 1159-1172, doi:10.1029/90JA02125, 1991.

Huber, K. P. and Herzberg, G.: Molecular Spectra and Molecular Structure. IV Constants of Diatomic Molecules, Van Nostrand, New York, 1979.

Kaye, J. A.: On the possibility of the reaction $\mathrm{O}+\mathrm{HO}_{2} \rightarrow$ $\mathrm{OH}+\mathrm{O}_{2}$ in $\mathrm{OH}$ airglow, J. Geophys. Res., 93, 285-288, doi:10.1029/JA093iA01p00285, 1988.

Kaufmann, M., Gusev, O. A., Grossmann, K. U., MartínTorres, F. J., Marsh, D. R., and Kutepov, A. A.: Satellite observations of daytime and nighttime ozone in the mesosphere and lower thermosphere, J. Geophys. Res., 108, 4399, doi:10.1029/2002JD003186, 2003.

Khachatrian, A. and Dagdigian, P. J.: Vibrational relaxation of $\mathrm{OH}$ by oxygen atoms, Chem. Phys. Lett, 415, 1-5, doi:10.1016/j.cplett.2005.08.131, 2005.

Langhoff, S. R., Werner, H., and Rosmus, P.: Theoretical transition probabilities for the OH Meinel system, J. Mol. Spectrosc., 118, 507-529, doi:10.1016/0022-2852(86)90186-4, 1986.

Lin, S. Y., Rackham, E. J., and Guo, H.: Quantum mechanical rate constants for $\mathrm{H}+\mathrm{O}_{2} \rightleftharpoons \mathrm{O}+\mathrm{OH}$ and $\mathrm{H}+\mathrm{O}_{2} \rightarrow \mathrm{HO}_{2}$ reactions, $\mathrm{J}$. Phys. Chem. A, 110, 1534-1540, doi:10.1021/jp053555v, 2006.

López-Puertas, M. and Taylor, F. W.: Non-local Thermodynamic Equilibrium in the Atmosphere, vol. 3, World Scientific, 2001.

Kalogerakis, K. S., Smith, G. P., and Copeland, R. A.: Collisional removal of $\mathrm{OH}\left(X^{2} \Pi v=9\right)$ by $\mathrm{O}, \mathrm{O}_{2}, \mathrm{O}_{3}, \mathrm{~N}_{2}$, and $\mathrm{CO}_{2}$, J. Geophys. Res., 116, D20307, doi:10.1029/2011JD015734, 2011.

Marshall, J., Kalogerakis, K. S., and Copeland, R. A.: Laboratory measurements of $\mathrm{OH}(v=2)$ collisional reactivation by oxygen atoms, American Geophysical Union Spring 2001 meeting, paper SA31A-21, 2002.

McDade, I. C.: The altitude dependence of the $\mathrm{OH}\left(X^{2} \Pi\right)$ vibrational distribution in the nightglow: Some model expectations, Planet. Space Sci., 39, 1049-1057, doi:10.1016/00320633(91)90112-N, 1991.

McDade, I. C. and Llewellyn, E. J.: Kinetic parameters related to sources and sinks of vibrationally excited $\mathrm{OH}$ in the nightglow, $\mathrm{J}$. Geophys. Res., 92, 7643-7650, doi:10.1029/JA092iA07p07643, 1987.

McDade, I. C. and Llewellyn, E. J.: Mesospheric oxygen atom densities inferred from night-time $\mathrm{OH}$ Meinel band emission rates, Planet. Space Sci., 36, 897-905, doi:10.1016/00320633(88)90097-9, 1988

McDade, I. C., Llewellyn, E. J., Mutagh, D. P., and Greer, R. G. H.: ETON 5: simultaneous rocket measurements of the $\mathrm{OH}$ Meinel $\Delta v=2$ sequence and $(8,3)$ band emission profiles in the nightglow, Planet. Space Sci., 35, 1137-1147, doi:10.1016/0032-
0633(87)90020-1, 1987.

Meinel, A. B.: OH emission bands in the spectrum of the night sky. I., Astrophys. J., 111, 555, doi:10.1086/145296, 1950.

Melo, S. M. L., Takahashi, H., Clemesha, B. R., and Simonich, D. M.: An experimental study of the nightglow $\mathrm{OH}(8-3)$ band emission process in the equatorial mesosphere, J. Atmos. Sol.Terr. Phy., 59, 479-486, doi:10.1016/S1364-6826(96)00053-3, 1997.

Mies, F. H.: Calculated vibrational transition probabilities of $\mathrm{OH}\left(X^{2} \Pi\right)$, J. Mol. Spectrosc., 53, 150-188, doi:10.1016/00222852(74)90125-8, 1974.

Miller, J. A., Kee, R. J., and Westbrook, C. W.: Chemical kinetics and combustion modelling, Annu. Rev. Phys. Chem., 41, 345387, doi:10.1146/annurev.physchem.41.1.345, 1990.

Milne, E. A.: Thermodynamics of stars, Handbuch der Astrophysik, 1930.

Mlynczak, M. G.: Atomic oxygen atomic hydrogen, and chemical heating rates derived from SABER, paper presented at the 37th COSPAR Scientific Assembly, COSPAR, Montreal, Cananda, 2008.

Murphy, R. E.: Infrared emission of $\mathrm{OH}$ in the fundamental and first overtone bands, J. Chem. Phys., 54, 4852-4859, doi:10.1063/1.1674762, 1971 .

Nelson, D. D., Schiffman, A., Nesbitt, D. J., Orlando, J. J., and Burkholder, J. B.: $\mathrm{H}+\mathrm{O}_{3}$ Fourier-transform infrared-emisson and laser-absortion studies og $\mathrm{OH}\left(X^{2} \Pi\right)$ radical: An experimental dipole-moment function and state-to-state Einstein A coefficients coefficients, Chem. Phys. Lett, 93, 7003-7019, doi:10.1063/1.459476, 1990.

Ohoyama, H., Kasai, T., Yoshimura, Y., and Kuwata, H.: Initial distribution of vibration of the $\mathrm{OH}$ radicals produced in the $\mathrm{H}+\mathrm{O}_{3} \rightarrow \mathrm{OH}\left(X^{2} \Pi_{1 / 2,3 / 2}\right)+\mathrm{O}_{2}$ reaction - Chemiluminescence by a crossed beam technique, Chem. Phys. Lett., 118, 263-266, doi:10.1016/0009-2614(85)85312-4, 1985.

Pastrana, M. R., Quintales, L. A. M., Brandão, J., and Varandas, A. J. C.: Recalibration of a single-valued double many-body expansion potential-energy surface for ground-state $\mathrm{HO}_{2}$ and dynamics calculations for the $\mathrm{O}+\mathrm{OH} \rightarrow \mathrm{O} 2+\mathrm{H}$ reaction, J. Phys. Chem., 94, 8073-8080, doi:10.1021/j100384a019, 1990.

Pickett, H. M. and Peterson, D. B.: Comparison of measured stratospheric OH with prediction, J. Geophys. Res., 101, 1678916796, doi:10.1029/96JD01168, 1996.

Pickett, H. M., Read, W. G., Lee, K. K., and Young, Y. L.: Observation of night $\mathrm{OH}$ in the mesosphere, Geophys. Res. Lett., 33, L19808, doi:10.1029/2006GL026910, 2006.

Picone, J. M., Hedin, A. E., and Drob, D. P.: NRLMSISE00 empirical model of the atmosphere: Statistical comparisons and scientific issues, J. Geophys. Res., 107, 1468, doi:10.1029/2002JA009430, 2002.

Sander, S. P., Abbatt, J., Barker, J. R., Burkholder, J. B., Friedl, R. R., Golden, D. M., Huie, R. E., Kolb, C. E., Kurylo, M. J., Moortgat, G. K., Orkin, V. L., and Wine, P. H.: Chemical Kinetics and Photochemical Data for Use in Atmospheric Studies, Evaluation Number 17, JPL Publication 10-6, Jet Propulsion Laboratory, Pasadena, CA, 2011.

Silveira, D. M., Caridade, P. J. S. B., and Varandas, A. J. C.: Dynamics of the $\mathrm{O}+\mathrm{HO}_{2}$ reaction using two DMBE potential energy surfaces: The role of vibrational excitation, J. Phys. Chem. A, 108, 8721-8730, doi:10.1021/jp049575z, 2004. 
Slanger, T. G., Jusinski, L. E., Black, G., and Gadd, G. E.: A new laboratory source of ozone and its potential atmospheric implications, Science, 241, 945-950, doi:10.1126/science.241.4868.945, 1988

Smith, A. K., Marsh, D. R., Mlynczak, M. G., and Mast, J. C.: Temporal variations of atomic oxygen in the upper mesosphere from SABER, J. Geophys. Res., 115, D18309, doi:10.1029/2009JD013434, 2010.

Smith, I. W. M., Herbst, E., and Chang, Q.: Rapid neutral-neutral reactions at low temperatures: A new network and first results for TMC-1, Mon. Not. R. Astron. Soc., 350, 323-330, doi:10.1111/j.1365-2966.2004.07656.x, 2004.

Spencer, J. E. and Glass, G. P.: Some reactions of $\mathrm{OH}(v=1)$, Int. J. Chem. Kin., 9, 111-122, doi:10.1002/kin.550090110, 1977.

Spitzer Jr., L.: The terrestrial atmosphere above $300 \mathrm{~km}$, in: The Atmospheres of the Earth and Planets, edited by: Kuiper, G. P., 213, Univ. Chicago Press, Chicago, USA, 1949.

Steinfeld, J. I., Adler-Golden, S. M., and Gallagher, J. W.: Critical survey of data on the spectroscopy and kinetics of ozone in the mesosphere and thermosphere, J. Phys. Chem. Ref. Data, 16, 911-951, doi:10.1063/1.1674762, 1987.

Toumi, R., Kerridge, B. J., and Pyle, J. A.: Highly vibrationally excited oxygen as a potential source of ozone in the upper-stratosphere and mesosphere, Nature, 351, 217-219, doi:10.1038/351217a0, 1991

Toumi, R., Houston, P. L., and Wodtke, A. M.: Reactive $\mathrm{O}_{2}(v \geq 26)$ as a source of stratospheric ozone, J. Chem. Phys., 104, 775-776, doi:10.1063/1.471642, 1996.

Turnbull, D. N. and Lowe, R. P.: New hydroxyl transition probabilities and their importance in airglow studies, Planet Space Sci., 37, 723-738, doi:10.1016/0032-0633(89)90042-1, 1989.

van der Loo, M. P. J. and Groenenboom, G.: Theoretical transition probabilities for the $\mathrm{OH}$ Meinel system, J. Chem. Phys., 126, 114314, doi:10.1063/1.2646859, 2007.

van der Loo, M. P. J. and Groenenboom, G.: Theoretical transition probabilities for the OH Meinel system, J. Chem. Phys., 126, 159902, doi:10.1063/1.2899016, 2008.

Varandas, A. J. C.: Faraday Discuss. Chem. Soc., 84, 353-356, doi:10.1039/DC9878400351, 1987.

Varandas, A. J. C.: On the ozone deficit problem: What are depletion cycles hiding?, Chem. Phys. Chem., 3, 433441, doi:10.1002/1439-7641(20020517)3:5<433::AIDCPHC433>3.0.CO;2-O, 2002.

Varandas, A. J. C.: Steady-state distributions of $\mathrm{O}_{2}$ and $\mathrm{OH}$ in the high atmosphere, and implications in the ozone chemistry, J. Phys. Chem. A, 107, 3769-3777, doi:10.1021/jp022483u, 2003.

Varandas, A. J. C.: Reactive and non-reactive vibrational quenching in $\mathrm{O}+\mathrm{OH}$ collisions, Chem. Phys. Lett., 396, 182-190, doi:10.1016/j.cplett.2004.08.023, 2004a.
Varandas, A. J. C.: Are vibrationally excited molecules a clue for the " $\mathrm{O}_{3}$ deficit problem" and " $\mathrm{HO}_{x}$ dilemma" in the middle atmosphere?, J. Phys. Chem. A, 108, 758-769, doi:10.1021/jp036321p, 2004b.

Varandas, A. J. C.: Reply to the comment on "Are vibrationally excited molecules a clue for the $\mathrm{O}_{3}$ deficit problem and $\mathrm{HO}_{x}$ dilemma in the middle atmosphere?", J. Phys. Chem. A, 109, 2700-2702, doi:10.1021/jp040745h, 2005a.

Varandas, A. J. C.: What are the implications of non-equilibrium in the $\mathrm{O}+\mathrm{OH}$ and $\mathrm{O}+\mathrm{HO}_{2}$ reactions?, Chem. Phys. Chem., 6, 453-465, doi:10.1002/cphc.200400335, 2005 b.

Varandas, A. J. C.: Trajectory binning scheme and nonactive treatment of zero-point energy leakage in quasiclassical dynamics, Chem. Phys. Lett., 439, 386-392, doi:10.1016/j.cplett.2007.03.090, 2007.

Varandas, A. J. C. and Zhang, L.: $\mathrm{OH}(v)+\mathrm{O}_{3}$ : Does chemical reaction dominate over non-reactive quenching?, Chem. Phys. Lett., 340, 62-70, doi:10.1016/S0009-2614(01)00364-5, 2001.

von Clarmann, T., Hase, F., Funke, B., López-Puertas, M., Orphal, J., Sinnhuber, M., Stller, G. P., and Winkler, H.: Do vibrationally excited $\mathrm{OH}$ molecules affect middle and upper atmospheric chemistry?, Atmos. Chem. Phys., 10, 9953-9964, doi:10.5194/acp-10-9953-2010, 2010.

Wallace, L.: The OH nightglow emission, J. Atmos. Sci., 19, 116, doi:10.1175/1520-0469(1962)019<0001:TONE > 2.0.CO;2, 1962.

Xie, D., Xu, C., Ho, T., Rabitz, H., Lendvay, G., Lin, S. Y., and Guo, H.: Global analytical potential energy surfaces for $\mathrm{HO}_{2}\left(\tilde{X}^{2} A^{\prime \prime}\right)$ based on high-level ab initio calculations, J. Chem. Phys., 126, 074315, doi:10.1063/1.2446994, 2007.

Xu, J., Hao, H., Smith, A. K, and Zhu, Y.: Using TIMED/SABER nightglow observations to investigate hydroxyl emission mechanisms in the mesopause region, J. Geophys. Res., 117, D02301, doi:10.1029/2011JD016342, 2012.

Yankovsky, V. A. and Manuilova, R. O.: Model of daytime emissions of electronically-vibrationally excited products of $\mathrm{O}_{3}$ and $\mathrm{O}_{2}$ photolysis: Application to ozone retrieval, Ann. Geophys., 24, 2823-2839, doi:10.5194/angeo-24-2823-2006, 2006.

Zhang, L. and Varandas, A. J. C.: Dynamics of the $\mathrm{OH}(v=$ $1,2,4)+\mathrm{O}_{3}$ atmospheric reaction, Phys. Chem. Chem. Phys., 3, 1439-1445, doi:10.1039/b010149o, 2001.

Zhao, M., Truhlar, D. G., Blais, N. C., Schwenke, D. W., and Kouri, D. J.: Are classical molecular dynamics calculations accurate for state-to-state probabilities in $\mathrm{H}+\mathrm{D}_{2}$ reaction?, J. Phys. Chem., 94, 6696-6706, doi:10.1021/j100380a033, 1990. 